as in the other, where so much time had not been lost, and where the nervous structures still retained a power of recovery. I doubt whether this patient will ever have any useful vision with it ; but the vision of the left eye, aided by stenopæic glasses, suffices for most of the ordinary purposes of life. I have seen the patient this week; she still has useful vision in the eye first operated on.

This case is perhaps calculated to dwell in the memory, and to fix there the lessons which it teaches, from the remarkable fact that in both eyes the atiack was alike; that its true nature was similarly misinterpreted in both; and that the patient escaped the one error with partial vision in the eye affected, and the other with barely a remnant.

Not to be tedious, I will mention only one other case, which is less painful, but not less instructive. I was asked lately to see an aged gentleman, whom his attendant described to me as having been suffering for a little time from what seemed to be a troublesome conjunctivitis. There was in this case little or no pain -only some uneasiness of a very slight character. The patient insisted, and continued to insíst, that he had a habit of sleeping with his face resting on his hand, and that he had unduly pressed upon the eye. His eye "felt a little bruised", but not enough to induce him to complain of it voluntarily. It was sensitive to light, but not enough to preventing him from writing comfortably when it was partially shaded, or even from pushing the shade off the eye when writing; and he was but little disturbed about it. He was a hale old gentleman, but considerably more than eighty years old, and therefore already suffering from some infirmities of the prostate. This insidious and painless conjunctivitis was then an almost painless but marked glaucoma, and belonging pathologically, if not in all its clinical characters, to the subacute class. The conjunctiva was little congested ; but the pupil was dilated, the eyeball of great hardness and tension, the cornea rough, the media dull, the optic papule cupped. On closing the sound eya, he discovered, much to his discomfiture, that he could not count fingers. Had I seen this old gentleman at the outset of his disorder, I should have counselled iridectomy, which alone could effect a cure. At his great age, and in the existing condition, in which iridectomy could not be relied upon to give more than partial results, I thought it best not to urge any operation, but to lay plainly before his friends the facts that the sight was seriously compromised, that iridectomy might be expected partially to restore it, and that no other known treatment offered any such prospect; but that against this must be weighed the objections to any sort of operation involving confinement to a room and the inhalation of an anæsthetic on an aged man of a peculiar temperament. Ultimately it was decided, with the concurrence of his relatives, who included members of our profession, and of Mr. White Cooper, who kindly came into consultation, not to operate. Bromide of potassium, and nervine tonics and sedatives of various kinds, were carefully administered, and a soothing local treatment ; but the disease was, as might be expected, unchecked; and the sight is lost in that eye.

It is not necessary, of course, here to speak of the usefulness of iridectomy in glaucoma. That belongs to the acquired facts of science and practice. Successful iridectomies in glaucoma are among the most striking, brilliant, and beneficent achievements of surgery ; and iridectomy in glaucoma ranks among the greatest surgical discoveries of the age. Here I wish only to point out, from the results of my own experience, which has not varied in this respect during the decade, that the sphere of usefulness of iridectomy is narrowed by the delays which commonly occur in general practice in recognising acute glaucoma, and the omission to apply at once the one and only remedy-iridectomy.

The ophthalmoscopic test affords the crucial evidence of the disease, but it need not remain unsuspected for want of a few simple rules. r. Wherever there are superficial inflammation of the eye, spontaneous dilatation of the pupil (generally oroid), hardness of the eyeball, pain, and diminution of vision, acute glaucoma may shreridly be suspected. 2. Wherever there is spontaneous dilatation of ihe pupil, accompanying slight redness of the eye, with hardness of the ball and affection of the vision, subacute glaucoma nay be suspected. The previous history generally includes the following subjective symptoms : rapidly increasing far-sightedness, haloes seen around lights at night, and occasional pains in the eyeball. I leave out of view any ophthalmoscopic or other of the optical tests of circumscription of the field of vision, for experts will already be on their guard. The external characters to which I refer in these short rules have been more or less typically conjoined in all the cases which have come under my notice. I am satisfied that it will be very useful that they should, in the minds of all practitioners, be so associated with glaucoma (to which they belong) as always to suggest by their occurrence the probable nature of the disease, and to lead to decisive investigation, and, if necessary, timely action. More eyes have been, and apparently still are, lost by the neglect or misapprehension of glaucomatous affections, than from any other single cause.

\section{ON THE NATURE OF THE SO-CALLED SARCINA} VENTRICULI.

By H. CHARLTON BASTIAN, M.D., F.R.S.,

Professor of Pathological Anatomy in University College; Physician to University College Hospital, etc.

THE interesting communication of Dr. Ferrier in last week's JoURNAL, with reference to the ease with which Sarcina may be procured from the blood of man and animals, and his comments upon this fact, tempt me to make a few remarks concerning this curious product.

Since its discovery by the late Professor Goodsir, Sarcina has pretty generally been accepted as a real living organism. The Rev. M. J. Berkeley has been inclined to look upon it as an unusual form of some one of our common mucors. For some months past, however, I have been of opinion that more evidence is needed upon this subject; and I would now ask whether Sarcina be really a living thing.

Some particulars concerning this interesting product which have come under my own observation have led me to believe that it is not a living organism; and I am further strengthened in this view by the observations of Dr. Ferrier. He seems, however, not to be aware of certain facts which have been already made known concerning Sarcina when he says: "True sarcinæ have never been found otherwise than in the bodies of animals or of their excreta." According to my colleague Dr. Tilbury Fox (Skin-Diserses of Parasitic Origin, p. 153 ), this product has been found by Dr. Lowe in stagnant water, and by Mr. H. O. Stephens on the surface of old bones which had been landed from a South American vessel. Moreover, in Nature, 1870, No. 36, I figured a specimen of Sarcina which had been produced in a flask containing an aqueous solution of ammonic tartrate and sodic phosphate. These were most characteristic specimens; and I have since, on several other occasions, procured them from similar solutions. Twice, also, during the last eighteen months, I have found small patches of wellmarked Sarcina on the surface of hay-infusions.

It is quite obvious, therefore, that the blood is not, as Dr. Ferrier is disposed to think, the only source of Sarcina,

My doubt concerning its real title to be considered as a living organism arose from the utter failure of ali attempts to develop it, and from the fact that a similar failure had attended the efforts of the Rev. M. J. Berkeley and others. In their case it might have been in part explained by the fact of the change of conditions to which the Sarcina (of stomach origin) were exposed, and to their removal from their natural habitat. No such extenuating circumstances, however, were possible in my case. Here were bodies of this kind found on several occasions in a particular saline solution, and yet they never seemed to increase in size or in numerical abundance after a certain stage. The conditions, being favourable enough for their origin, ought certainly to have led either to their multiplication or to their development, or to both. This is what inevitably occurs with all real Fungus-germs. I have, moreover, watched Sarcina long and attentively, and have never been able to see the slightest evidence of the occurrence of anything like spontaneous fission. And, after alluding to some statements which had been made upon this subject coupled with his own observations, Dr. Tilbury Fox says : "I am compelled, then, to disbelieve in the formation of sarcinæ by fissiparous division" (loc. cit., p. 160).

I am therefore, inclined to think, that until some one has actually seen Sarcina undergo a spontaneous process of fission, or has succeeded in inducing it to develop into some more unmistakable organic form, there is not sufficient evidence to show that it is really a living organism.

My position in this respect is, I think, strengthened by other considerations, which lead me to believe that it is a kind of concretionperhaps partly organic and partly mineral in its constitution. Some recent researches have revealed the frequency of the occurrence of such concretions in organic and other solutions. One of the essential conditions for the occurrence of sarcina, however, seems to be the presence of a phosphate in the fluid in which it is to form.

Whilst inclining to this view, I met with a statement of Lebert's which seemed to favour the notion. In describing a specimen which was found in large quantities in the fluids vomited by a woman suffering from cancer of the stomach, he says : "En comprimant les lames de verre entre lesquelles nous examinions ces préparations, nous avons été frappé de la sensation sablonneuse, qui ne pouvait après mûr examen tenir qu'à la dureté de sarcines, ce qui nous faisait supposer qu'elles avaient une envelope minérale" (quoted in Robin's Végétaux Parasites, 1854 , p. 337). It is a fact, also, that the Sarcina met with in ammonic tartrate solutions, as well as that from the stomach, has always been found amongst the sedimentary deposits. And, again, in other ammonic tartrate solutions, in which there has been either no Sarcina of 
the ordinary description, or only a small quantity of it, a sedimentary matter has been found having a very strong general resemblance to Sarcina, though its appearance has been such as to make it almost certain that it is a kind of modified crystalline matter (perhaps somewhat analogous to Mr. Rainey's calculi), rather than a living substance. This variability, moreover, is not confined to the Sarcina which I have met with in my experiments; it is met with, also, in that from the stomach. Robin's figures (loc. cit., pl. xii, fig. I) show a considerable variation in the ultimate pattern of different specimens of Sarcina.

These, and other facts and opinions with reference to Sarcina and somewhat similar products, have for some time been embodied in my work on the The Beginnings of Life, which is shortly to appear. And now it seems to me that such views are strengthened by Dr. Ferrier's recently recorded observations.

Sarcina has been found by him in cases where there has been an " entire absence of putrefactive changes, and no trace of any of the common organisms." He says : "The blood in which sarcinæ had developed to an enormous extent, always retained its alkalinity. There was no sign of putrefaction or fermentation, and no gaseous evolution." Now, I am inclined to believe that it is absolutely impossible for any real living germs to develope to an "enormous extent" in any fluid without an obvious amount of "gaseous evolution" occurring. If, as Dr. Ferrier tells us, this is not the case with Sarcina, we are driven to conclude either that Sarcina is wholly different in this fundamental respect from all other fungus-germs, or else that it is not a living organism at all.

My object in making the present remarks has been merely to direct the attention of Dr. Ferrier and other workers to some of the difficulties which have appeared to me to beset this question, in order that, if possible, they may throw some additional light upon the subject.

In case others should try to procure Sarcina in ammonic tartrate and sodic phosphate solutions, I may as well state that, although I have met with it on ten or twelve different occasions in such fluids, it is by no means to be produced at will. On many occasions I have failed to obtain it, although the solutions and the conditions were, so far as I could make them, similar to those which had yielded Sarcinæe on previous occasions. My occupation with other more important parts of the investigation, in the course of which these curious products were found, has hitherto prevented my making any more thorough observations concerning their nature, and their mode of origin in such solutions.

\section{KOUMISS IN THE TREATMENT OF PHTHISIS.}

\section{By VICTOR JAGIELSKI, M.D.}

THE study of the history of any country naturally comprises the consisideration of the habits, diet, and domestic arrangements of its people. Thus old historical records mention the use of koumiss in Tartary, and bland in Shetland. In Tartary, koumiss has been specially favoured as a beverage from time immemorial, through the influence of religious observances; for, not being a distilled liquor, it escapes the Moham medan proscription, "Qui Muhammedi doctrinam sequuntur, lege Corano præscriptâ vinum adustum sumere vitantur," says one of the authors on that country. This ban gives that country prohibition against mania potatoria and delirium tremens, which, as well as phthisis, are amongst the unknown indigenous diseases in Tartary.

It is the general cause of the latter disease, and the immunity from it, which characterise the region of the Kirghese steppes, that I will now discuss. Popular belief ascribes this exemption to climatic features in some parts, and to peculiarities of soil, etc., in others ; but throughout all Russia the opinion prevails, that the common use of koumiss as both drink and food is the paramount cause.

According to Dr. E. Charlton of Newcastle, Iceland and the Faroe Islands are blessed in this respect for similar reasons as Tartary; the whey-like liquor which he mentions as the national beverage there being only a modification of koumiss. The views of Dr. Charlton are confirmed by the several writers upon Iceland and the islands of Shetlands whose works I have consulted in this connexion.

Dr. Williams's suggestion, that the use of "Muggy" is the reason of this exemption in Iceland, does not hold good for Tartary, as my own knowledge enables me to state that cod-liver oil is not employed there under any name.

This common cause, operating with such happy effect in countries so widely distant, is a pleasing study for all impartial observers. My observations and experience lead me to the conclusion that it is the diet of fermenting milk, and not topographical influence, which produces this exemption among two peoples so different as the Kirghese Tartars and the northern islanders. Though in one country the koumiss is made from mare's milk, and in the other from cow's milk, the product is practically the same, as it would be also if made from any other kind of animal milk, by proper adjustments. As I can see no other point of agreement between these two countries as to their exemption from phthisis, the conviction forces itself upon me, that the coincidence can only be due to the use of koumiss, bland, or syre.

It is a historical fact, that those people who may habitually consume these dietetic substances are free from consumption, provided there be no hygienic influences in conflict with this diet. I use the titles koumiss, bland, and syre, synonymously; for they belong to the same ancient Scandinavian beverage, in one or other of its modified forms, called in Tartary koumiss, in Shetland bland, and in Iceland syre, and which has been introduced by me in British practice under the names of "full", "medium", and "whey" koumiss. As koumiss proper, however, contains all the caseine of the milk, it is much more nutritious than the bland or syre, or whey-koumiss.

The tendency of koumiss to produce a layer of fat on the subcutaneous cell-tissues in a comparatively short time, its great value in improving the digestive powers, and in promoting the due assimilation of food, prevent the decay and waste of weakly constitutions, to which all phthisical persons are liable. This is a fact which no one can deny who has ever had any experience in the use of koumiss; for it is ever prompt to justify its claim to the foremost rank as a means of preventing disease, no less than as a curative when disease has commenced.

The deductions from Dr. Charlton's own experience teach us that, in proportion as this beverage has been left off in Shetland, and tea and coffee have been substituted, so has phthisis increased.

Tartary, where the native cases of incipient phthisis are very rare, offers, according to all travellers and professional gentlemen who have resided there for some time, some particulars which are of interest, and worthy of explanation in this place. That country belongs, according to Alexander von Humboldt, to the so-called "continental climate", where the summer is exceedingly dry, the heat very great, with scarcely any rain; whereas in winter continuous frosts are prevalent. But that it cannot be this climate which assures an almost complete exemption from phthisis, becomes obvious from the fact that consumptives who may reside there, without using the koumiss treatment, would suffer collapse as soon as and sooner than anywhere else. Besides, we know to-day how it victimises the poor invalids to send them to a climate of high temperature. The tubercular deposits tend here more easily to softening. The constitution becomes weaker, flabbier. Local and general liquefaction and colliquation are thus caused prematurely. To avoid these consequences, a retreat to a higher level and a cooler temperature is now preferred for consumptive patients. French physicians select places which have the proper conditions both for summer and winter residence.

Generally, it is believed that malaria gives immunity from tubercular lung-disease. Negroes, who stand best of all the hottest climate, suffer chiefly with consumption; but they enjoy an almost complete exemp. tion from malarial diseases. The natural inference is, that a temperate region is the more suitable for the residence of consumptive patients, and that an absolute curative influence cannot be ascribed to any climatic condition.

Protection from certain injurious winds, and other advantages of a favourable position, are decidedly points of great importance in the choice of a place best suited for our patients. High elevations afford only a temporary relief, unless patients make their residence permanent there. But, reason as we may, the fact presses upon our conviction, that the real focus for attention is the process of nutrition; and it is equally obvious that we must also consider, in this connexion, general dietetic and hygienic rules. Koumiss, then, by reason of its chemical and therapeutic properties, is a most advantageous means of treating phthisis, whether preceded or accompanied by bronchitis or pneumonia in a weakly constitution; but it is observed that residence during a hot season in Tartary is merely an agreeable auxiliary to the koumiss treatment, by enabling patients to drink koumiss much more freely. A liberal and uninterrupted perspiration carries off rapidly all the water of the koumiss which is not excreted otherwise. But mare'smilk koumiss would prove much more inefficient in a cooler climate than in a hot one. Therefore I always prescribe the cow's full koumiss, which suits best this climate. The benefit from mare's-milk koumiss is considerably retarded by cold and wet. This is natural, when we remember that, if very large quantities of koumiss must be drank in order to be effective, this can be done with impunity only by the powerful aid of a free action of the skin and kidneys. In summer copious perspiration is the bodily safety-valve of the animal heat and health. In winter, we know that diuresis takes its place; but at the same time we must not forget that, through the elimination of a large 